\title{
THE "SALES AGENT" PROBLEM: EFFORT/LEISURE ALLOCATION UNDER PERFORMANCE PAY AS BEHAVIOR TOWARDS RISK
}

\author{
C. BRAM CADSBY, FEI SONG and NICK ZUBANOV*
}

\begin{abstract}
The choice between safe and risky assets represents behavior towards risk: more risk-averse investors buy more safe assets. We develop and test a general model that applies this intuition to the time allocation between risky effort and risk-free leisure under linear incentives. When risk increases with effort, risk-averse agents choose less effort, but when risk is independent of effort, effort choice is unaffected by risk preferences. In many incentive contracts, income risk is multiplicative with, rather than additive to effort, sales commissions being one example. In such cases, lower effort by the risk-averse is a hitherto undocumented behavior towards risk (JEL C91, M52, J33)
\end{abstract}

\section{INTRODUCTION}

Consider a sales agent who earns a unit commission for each successfully completed transaction. A transaction succeeds with probability $p$ after each customer contact. The more contacts, $n$, he or she makes, the higher are the agent's expected earnings $(=n p)$, but so too is the variance of those earnings $(=n p[1-p])$. Given an alternative risk-free activity such as leisure, how will the agent's risk attitude affect the number of customer contacts he or she chooses to make?

The above question is inspired by the classic problem of a wealth holder who must allocate assets between risk-free cash and a portfolio of risky assets (Tobin 1958). ${ }^{1}$ Assuming that the

*We acknowledge funding from Social Sciences and Humanities Research Council of Canada Grant \#430-20110512. We also thank Michael Hoy for helpful comments on an earlier draft.

Cadsby: Professor, Department of Economics and Finance, University of Guelph, Guelph, ON N1G 2W1, Canada. Phone 1-519-8244120, Fax XXXX, E-mail bcadsby@uoguelph.ca

Song: Professor, Ted Rogers School of Management, Ryerson University, Toronto, ON M5B 2K3, Canada. Phone 1-416-9795000, Fax XXXX, E-mail fsong@ryerson.ca Zubanov: Professor, Department of Economics, University of Konstanz, Konstanz, 78464, Germany. Phone 49-7531 88-4404, Fax XXXX, E-mail nick.zubanov@unikonstanz.de

1. Tobin's (1958) analysis assumes a given amount is to be invested in monetary assets that have no default risk and considers how to divide such assets between risk-free cash and a consolidated stock (consol) or perpetuity that is risky because of its association with some probability of capital gain or loss. Others have extended the analysis to encompass riskiness of an asset can be fully captured by the variance of the distribution of its returns, ${ }^{2}$ Tobin shows that a more risk-averse investor will choose to hold a greater portion of his/her portfolio in cash, sacrificing expected return to avoid risk. Similarly, the sales agent in our example must divide his or her time between leisure, which yields a risk-free return, and contacting potential customers, which may have a higher expected return but a higher risk as well. Intuitively, just like the more risk-averse investor, the more risk-averse sales agent should exhibit behavior toward risk, sacrificing expected return by allocating less time to customer contacts and more to risk-free leisure. In the mean-variance framework, the amount of effort depends on risk aversion when effort exertion increases not only the expected value of the endeavor, but also the variance or riskiness of the endeavor as in the case of our sales agent. In contrast, if increased effort has no effect on the variance of the payoff,

the division of wealth generally between a risk-free asset and a portfolio of risky securities on the efficient frontier (e.g., Sharpe 1964).

2. Either a quadratic utility function or a two-parameter distribution of returns is sufficient for this to be the case.

\section{ABBREVIATIONS}

CARA: Constant Absolute Risk Aversion ECUs: Experimental Currency Units GSOEP: German Socio-Economic Panel TC: Total Cost UC: Unit Cost WTR: Willingness to Take Risks 
risk attitude will have no effect on the optimal amount of effort exerted. In this paper, we generalize and examine the robustness of this simple intuition beyond the special case represented by the mean-variance framework, test it experimentally, and discuss its implications for incentives.

The existing empirical literature studying behaviors toward risk under performance incentives focuses on the sorting of more risk-tolerant agents into jobs offering stronger incentives, which is indeed commonly observed in the labor market (Bellemare and Shearer 2010; Dohmen et al. 2011; Grund and Sliwka 2010; Lo, Ghosh, and Lafontaine 2011). However, since firms typically offer standard pay contracts to all within a certain employee group, sorting is never perfect, leaving employees with varying risk preferences facing similarly risky incentives. For instance, the data from the German Socio-Economic Panel (GSOEP) show that although employees receiving performance-based pay have, on average, a higher willingness to take financial risks than those whose pay is fixed (2.25 vs. 1.98 out of a maximum of 10), the variance of risk attitudes within the two groups (4.65 and 4.66) is comparable with the overall sample variance, 4.67..$^{3}$

Less is known about how agents with different risk preferences respond to the same incentives (see Section II for a literature review). In particular, the conditions under which risk preferences will or will not affect the agent's time allocation between risky and risk-free activities in response to given incentives have not been systematically studied. Our paper fills this gap. Consistent with previous theoretical work, our theory (Section III) predicts in a very general setting that, all else equal, the link between the time spent on the risky activity (labeled "effort") and risk aversion under given incentives will depend on how output- and consequent pay-uncertainty is related to such effort. If earnings and effort are both measurable in monetary terms so that utility depends on the difference between them, effort will not be affected by risk preferences when earnings uncertainty is additive to and independent of effort (the additive noise case in Section III). This is a known result stemming from the linear agency model (e.g., Sloof and van Praag 2008). In contrast, when earnings uncertainty increases with

3. Our calculations are based on the GSOEP 2009 data because 2009 was the only year that the question on the willingness to take financial risks was asked. A total of 6,214 respondents answered this question, of whom 3,934 received performance-based pay and 2,280 received fully fixed pay. effort (as in our multiplicative-noise and all-ornothing cases), more risk-averse agents will supply less effort. Thus, the particular combination of linear incentives, sorting imperfections and performance measurement technology that are associated with risk that increases with effort will imply effort withdrawal/intensification as behavior toward risk by risk-averse/risk-loving agents. ${ }^{4}$ This combination is quite realistic and observed frequently enough to render our study empirically relevant and important.

As a real-life example of behavior toward risk under linear incentives with multiplicative noise, consider the case of a German personnel search firm. ${ }^{5}$ The firm employs recruitment consultants who search for and introduce candidates to corporate clients. If a client hires the candidate a consultant has introduced, the consultant receives a predefined percentage of the deal's gross profit (the same for all consultants) as a commission. Thus, the incentive pay practiced by the firm corresponds to the multiplicative noise case we consider. ${ }^{6}$ An external agency surveys the newly hired consultants shortly after hiring, collecting, among other information, data on their (incentivized) willingness to take risks (WTR). Figure 1 reports the average number of client meetings per month conducted by 88 newly hired consultants grouped by their WTR. Just as our theory predicts, there is a positive and statistically significant ( $p$ value 0.05 ) relationship between WTR and the monthly average number of meetings with potential clients: less risk-averse consultants meet more potential clients because this leads to higher expected earnings, albeit with a higher variance.

While the above correlation is suggestive, a thorough test of our theory requires comparing behavior under multiplicative and additive noise, as well as isolating sources of heterogeneity in behavior that are outside our focus, such as those stemming from differences in the costs of effort. To this end, we carry out an experiment in which

4. A loss-averse agent behaves in a manner that is qualitatively the same as a risk-averse agent, which we show as an extension to our model.

5. The case presented uses data from another unrelated research project in progress in which one of the authors of this paper is involved.

6. It was surprisingly hard, given the ubiquity of production functions with additive noise in the literature on incentive contracts, to come up with a real-life example of additive noise to one's incentivized output. For noise to be additive to output, the marginal product of effort should not be affected by uncertainty. We could not identify situations in which this would be the case. 


\section{FIGURE 1}

Willingness to Take Risks and Average Number of Client Meetings per Month.

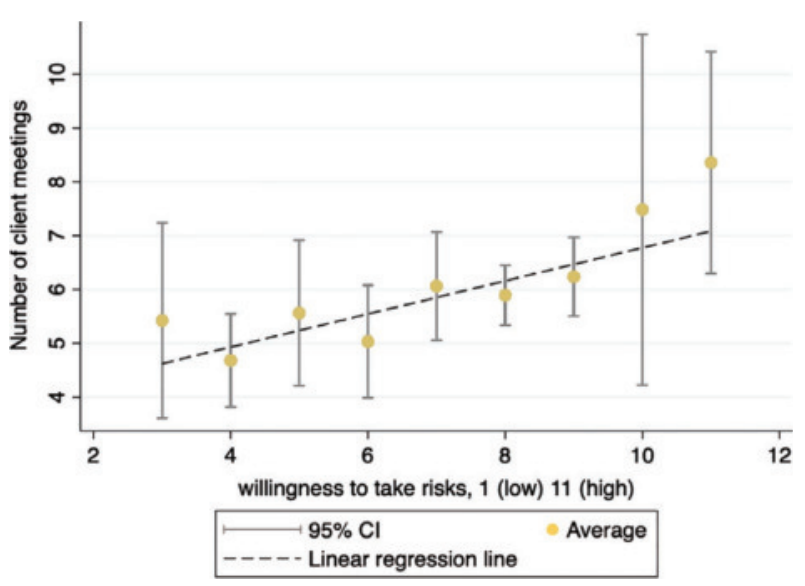

Note: This figure shows the monthly average number of potential client meetings conducted by 88 newly hired recruitment consultants, grouped by their self-reported willingness to take risks (WTR). The data come from a German Personnel Search Firm, and are part of another research project in which one of us is involved. The firm pays its recruitment consultants a commission per each successful recruitment deal on top of a fixed salary. A client meeting results in a deal with a certain probability (statistically, one out of ten meetings brings a deal). In producing the above statistics, we control for differences between labor markets in which the firm operates and time trends by means of regression analysis. The relationship depicted above is statistically significant. The coefficient on WTR is 0.54 , and its $p$ value is 0.05 in the main specification, which is the Tobit linear regression with errors clustered by consultant ID. The choice of specification reflects the fact that the observed outcome (number of client meetings per month) is censored at zero. The relationship becomes weaker when we exclude observations with WTR $=11$ or 10 ( $p$ value 0.147$)$, but remains positive and economically meaningful, with the coefficient on WTR of 0.37

we recreate the differing conditions under which the link between risk aversion and effort should or should not exist (Section IV). Every participant in our experiment had to decide on the number $n$ of "investment certificates" to acquire in each of four treatments: the control, administered first, and the additive noise, multiplicative noise, and all-or-nothing noise treatments administered in different randomly determined orders. (Only one, randomly chosen treatment was payoff relevant.) We choose a nonreal effort task to gain control over the opportunity cost of effort, captured in the price of investment certificates, to ensure effort levels can be observed, and to make our design consistent with the assumption of the linear agency model that effort is measurable in monetary terms. This design choice allows us to begin with the canonical linear agency model with additive noise, and then extend it to examine, holding all else constant, how a change to multiplicative or all-or-nothing noise affects effortlevel choices.

The prices and expected returns per certificate are the same in each treatment. However, the determination of actual returns varies by treatment: 10 experimental currency units (ECUs) per certificate in the control; 10 ECUs plus a mean-zero random amount added to the total in the additive noise treatment; an equiprobable draw of 0 or 20 ECUs determined independently for each certificate in the multiplicative noise treatment; and an equiprobable draw of 0 or 20 ECUs determined for all purchased certificates at once in the all-or-nothing treatment. Thus, the earnings variance is zero in the control, independent of $n$ under additive noise, and increasing with $n$ under multiplicative, and increasing even more steeply under all-or-nothing noise.

Our empirical results (Section V) support our theory. In particular, we find no relationship between the self-reported WTR and the choice of $n$ in the additive noise treatment, a positive relationship in the multiplicative noise treatment, and a stronger positive relationship in the all-ornothing treatment. Consistent with these findings, the variance in the choice of $n$ is highest under all-or-nothing noise, lower under multiplicative noise, and still lower under additive noise. Of the 163 of our 180 participants who choose the payoff-maximizing number of certificates in the control, individual choices of $n$ are consistent with our model across all treatments in 117 cases ( $72 \%$ of the total). Of those cases, $80 \%$ are consistently risk averse or neutral and the rest are risk loving, which is close to the shares of risk types reported in earlier studies. ${ }^{7}$

Taken together, our results imply that differences in individual effort under the same incentives cannot be explained by different costs of effort alone. In fact, under conditions that we clearly define and test, effort choice ceteris paribus is a behavior toward risk. Managers should take this behavior into account when deciding on incentive pay plans and corresponding performance measures, in ways that we elaborate in the concluding discussion.

7. $76 \%-80 \%$ are revealed risk-averse or risk-neutral in Holt and Laury (2002), and 79\%-93\% in Eckel and Grossman (2002, 2008). See also Reynaud and Couture (2012). 


\section{NOISE, RISK PREFERENCES, AND EFFORT UNDER A GIVEN LINEAR INCENTIVE SCHEME}

The notions of additive and multiplicative noise are not new. Zabojnik (1996), Raith (2008), and Rantakari (2008) all allow for the marginal productivity of effort to be affected by a multiplicative random variable in their models of optimal incentive schemes given the agent's risk preferences. None of these models, however, considers how agents with different levels of aversion to risk would respond to a given incentive scheme - the question we study.

In a pioneering theoretical study, Baker and Jorgensen (2003) do begin to examine this question. They distinguish between two types of output uncertainty in their model: multiplicative noise - a random coefficient attached to effort in the production function, and additive noise - a random term added to the product of an agent's effort and the multiplicative-noise coefficient. For the specific case of the linear incentive scheme and constant absolute risk aversion (CARA) utility, they derive a negative relationship between the agent's degree of risk aversion and his or her optimal effort level under multiplicative noise. In contrast, for the case of additive noise and costs of effort measurable in monetary terms, Sloof and van Praag (2008) show for a general utility function that risk preferences do not affect optimal effort. We replicate Sloof and van Praag's (2008) result for additive noise and derive theoretical predictions for a general utility function under multiplicative noise.

A related literature on background risk studies the effects of random fluctuations in investor wealth on the demand for risky assets. Gollier and Pratt (1996) introduce the concept of risk vulnerability meaning a higher degree of absolute risk aversion when background risk increases. They also derive the conditions for risk vulnerability for the case of additive background risk. Franke, Schlesinger, and Stapleton (2006) do so for the case of multiplicative background risk. Beaud and Willinger (2015) test for, and find, risk vulnerability in the presence of additive background risk. Most of the participants in their experiment invest the same or a lower proportion of their portfolio in a risky asset when a zero-mean noise term is added to their wealth. Our study differs from this literature in focusing on risks endogenous to effort decisions rather than on exogenous background risk. However, we will later argue that the presence of such background risk can magnify the extent to which effort is reduced in order to mitigate risk related to effort.
Turning to the empirical literature on risk aversion and effort, Sloof and van Praag $(2008,2010)$ use two different real-effort experimental designs to examine the risk aversion-effort link under additive noise, and obtain contrasting results. In the 2008 study, their design requires the allocation of a fixed amount of effort between two tasks, making the opportunity cost of effort allocated to one task measurable in monetary terms as the foregone benefit of allocating that effort to the other task. The ability to measure effort in monetary terms is critical to the design because it implies that the optimal choice of effort under a compensation scheme linear in output is independent of the amount of additive noise in the environment. The experimental findings confirm their prediction: there was no change in the participants' effort levels as they moved from the low- to the high-variance treatment.

In their later study, Sloof and van Praag (2010) use an experimental design in which subjects choose how much effort to exert on a single task. Thus, it is no longer possible to assume effort can be measured in monetary terms as in the 2008 study. In this environment, their experimental results show that effort increases both with the variance of the additive noise term and with risk aversion. In their Proposition 1, they delineate conditions under which this is consistent with a model in which effort cannot be measured in monetary terms. ${ }^{8}$ Unlike either of the Sloof and van Praag studies, we are concerned with comparing the effects of additive versus multiplicative and all-or-nothing noise on the decisions of individuals with differing attitudes toward risk. To provide clear contrasting predictions and meaningful empirical tests for the additiveversus multiplicative- versus all-or-nothing-noise specifications, we model effort in monetary terms and choose a simple nonreal-effort experimental design that is consistent with this modeling choice.

Cadsby, Song, and Tapon $(2007,2016)$ design a real-effort, multiplicative noise environment by asking subjects to solve anagrams (Cadsby, Song, and Tapon 2007) or calculate sums (Cadsby, Song, and Tapon 2016), both tasks with uncertain output per unit of effort. In both studies,

8. Sloof and van Praag (2010) also mention two other potential reasons for the differing results: a possible lack of understanding by subjects in the more complex experimental task from the 2008 study and reference-dependent preferences in the 2010 study. One of the reasons we chose a nonreal-effort task was to minimize task complexity, while nonetheless ensuring that effort is measurable in monetary terms. 
participants are randomly assigned to fixed pay in some rounds and piece rates in others. While on average participants perform better under piece rates than under fixed pay, this effect is attenuated for the more risk averse. In fact, many of the most risk-averse participants actually perform worse under piece rates than under fixed pay. Cadsby, Song, and Tapon (2016) put forward three possible explanations for this result. The first is the withholding of effort by more riskaverse participants in the financially uncertain piece-rate environment. The second is choking under the pressure of financial uncertainty dependent on how successfully the participant deals with the assigned real-effort task. The third is that more risk-averse subjects perform better on average under fixed pay compared to those who are less risk averse, leaving less room for improvement under piece rates. However, because effort is not directly observed, they are unable to identify definitively the relative importance of each of these three potential explanations for their results. Zubanov (2015) examines the risk aversion-effort relationship in a real-effort experiment in which the reward per unit of output is given with a certain known probability, a design directly corresponding to the sales-agent example in the introduction. He finds a negative link, which flattens out when an earnings target is introduced. Neither Cadsby, Song, and Tapon $(2007,2016)$ nor Zubanov (2015) uses an additive noise treatment in their experiments.

More research on risk aversion and effort under multiplicative versus additive noise is required in several directions in order to develop a fuller picture of the existence, relevance and importance of effort withdrawal as behavior toward risk. First, all studies examining multiplicative noise derive their predictions for a specific utility function. It is unclear to what extent those predictions are an artifact of using CARA utility. Second, no study compares behavior under additive- versus multiplicative- and all-or-nothing-noise treatments. This comparison is necessary in order to test systematically the contrasting predictions of the underlying theory under otherwise identical circumstances. This is particularly true because of the sensitivity of the predictions for behavior toward risk under additive noise as demonstrated by Sloof and van Praag $(2008,2010)$. Third, the findings of the existing studies may be partly affected by differences in unobserved personal characteristics, such as costs of effort and susceptibility to choking under pressure, both possibly correlated with risk preferences. The relationship between risk aversion and effort cannot be thoroughly tested without isolating it from these potentially confounding factors. This requires a setting in which the cost of effort is controlled, performance anxiety is minimized, and effort is directly observable rather than inferred from output. Moving forward on these three issues is the objective of this study.

\section{THEORY}

Consider an agent working under a linear incentive contract comprising a fixed income $I$ and a unit piece rate. The agent's total net income, $I+g(n, \epsilon)-c(n)$, is determined by: (1) his/her chosen effort level $n$ producing output $g(n, \epsilon)$ at a cost measurable in monetary terms and represented by a convex function $c(n)$, and (2) a noise term $\epsilon$ randomly drawn from a probability distribution with a known probability density function $f(\epsilon, n)$. Since our experiment asks subjects to select an effort level from a menu that links each available effort level with a fixed monetary cost, the cost of effort $c(n)$ and the value of output $g(n, \epsilon)$ are both denominated in identical monetary units, and are the same for all agents. Hence, we assume that the utility function may be written as $u(I+g(n, \epsilon)-c(n))$. The agent may be risk averse, risk neutral or risk loving, in which cases his/her utility function is concave, linear, and convex in net income, respectively.

The agent chooses a level of effort that maximizes his/her expected utility given the incentive contract, the costs of effort, and the noise distribution:

$$
\begin{aligned}
\max _{n} E U(n) & =E_{\epsilon}[u(I+g(n, \epsilon)-c(n))] \\
& =\int u(I+g(n, \epsilon)-c(n)) f(\epsilon, n) d \epsilon,
\end{aligned}
$$

where $E_{\epsilon}[\cdot]$ means expected value with respect to the noise term $\epsilon$, the only random variable in our model. The optimal level of effort is determined from the following first-order condition:

$$
\begin{aligned}
0 & =E U^{\prime}(n)=\int u^{\prime}(I+g(n, \epsilon)-c(n))\left(g^{\prime}(n, \epsilon)\right. \\
& \left.-c^{\prime}(n)\right) f(\epsilon, n) d \epsilon+\int u(I+g(n, \epsilon) \\
& -c(n)) \frac{f^{\prime}(\epsilon, n)}{f(\epsilon, n)} f(\epsilon, n) d \epsilon
\end{aligned}
$$




$$
\begin{aligned}
& =E_{\epsilon}\left[u^{\prime}(I+g(n, \epsilon)-c(n))\right] \\
& +E_{\epsilon}\left[\left(g^{\prime}(n, \epsilon)-c^{\prime}(n)\right)\right] \\
& +\operatorname{cov}_{\epsilon}\left[u^{\prime}(I+g(n, \epsilon)-c(n)), g^{\prime}(n, \epsilon)-c^{\prime}(n)\right] \\
& +\operatorname{cov}_{\epsilon}\left[u(I+g(n, \epsilon)-c(n)), \frac{f^{\prime}(\epsilon, n)}{f(\epsilon, n)}\right]
\end{aligned}
$$

Equation (2) elucidates the basic intuition behind our main result: risk preferences, captured in the $u^{\prime}(\cdot)$ and $u(\cdot)$ terms above, affect the agent's optimal effort choice only when the marginal product of effort, $g^{\prime}(n, \epsilon)$, depends on the noise $\epsilon$, or when the distribution of the noise $f(\epsilon, n)$ depends on effort $n$, or both..$^{9,10}$ Otherwise, with $g^{\prime}(n, \epsilon)=g^{\prime}(n)$ and $f^{\prime}(\epsilon, n)=0$, both covariance terms in (2) become zero, and the optimal effort is determined from $E_{\epsilon}\left[\left(g^{\prime}(n, \epsilon)-c^{\prime}(n)\right)\right]=0$, which does not depend on risk preferences.

In what follows, we apply this intuition to the following three specifications of noise in the production function.

ADD: additive noise, in which output is given by $g(n, \epsilon)=p n+\epsilon$, where $0<p<1$ is constant and the additive noise term $\epsilon$ is independent of $n$. In this case, the marginal product of effort, $g^{\prime}(n, \epsilon)=p$, does not depend on the noise, and the noise distribution does not depend on effort, giving $f^{\prime}(\epsilon, n)=0$. Accordingly, just as in Sloof and van Praag $(2008,797)$, the first-order condition (2) for the optimal effort under ADD is simplified to

$$
0=E U_{A D D}^{\prime}\left(n^{* A D D}\right)=\left(p-c^{\prime}\left(n^{* A D D}\right)\right)
$$

MULT: multiplicative noise, in which $g(n, \epsilon)=\epsilon n$ follows a binomial distribution with mean $p n$ and standard deviation $\sqrt{n p(1-p)}$, approaching normal for sufficiently large $n p[1-p]$, which we assume. Therefore, the empirical frequency of success, $\epsilon$, follows an approximately normal distribution with mean $p$ and standard deviation $\sqrt{p(1-p) / n}$ on the range of its possible values between 0 and 1 . This specification corresponds directly to our sales agent example, in which success or failure of each contact is determined independently of other contacts. With the marginal product of

9. In Equation (2) and elsewhere in the paper, “'” means the derivative with respect to $n$.

10. The derivation above uses the fact that the expectation of the product of two random variables equals the product of expectations plus the covariance, and that $E_{\epsilon}\left[\frac{f^{\prime}(\epsilon n)}{f(\epsilon n)}\right]=$ $\int f^{\prime}(\epsilon n) d \epsilon=\frac{\partial}{\partial n}\left(\int f(\epsilon n) d \epsilon\right)=\frac{\partial}{\partial n}(1)=0$. effort depending on the noise, $g^{\prime}(n, \epsilon)=\epsilon$, and the noise distribution depending on effort, the first-order condition for the optimal effort under MULT becomes

$$
\begin{aligned}
& \text { (4) } 0=E U_{M U L T}^{\prime}\left(n^{* M U L T}\right) \\
& =E_{\epsilon}\left[u^{\prime}\left(I+n^{* M U L T} \epsilon-c\left(n^{* M U L T}\right)\right)\right] \\
& \text { - } E_{\epsilon}\left[\left(\epsilon-c^{\prime}\left(n^{* M U L T}\right)\right)\right]+ \\
& +\operatorname{cov}_{\epsilon}\left[u^{\prime}\left(I+n^{* M U L T} \epsilon-c\left(n^{* M U L T}\right)\right)\right. \text {, } \\
& \left.\epsilon-c^{\prime}\left(n^{* M U L T}\right)\right]+ \\
& +\operatorname{cov}_{\epsilon}\left[u\left(I+n^{* M U L T} \epsilon-c\left(n^{* M U L T}\right)\right),\right. \\
& \left.\frac{f^{\prime}\left(\epsilon, n^{* M U L T}\right)}{f\left(\epsilon, n^{* M U L T}\right)}\right] \text {. }
\end{aligned}
$$

Note that $\frac{f^{\prime}(\epsilon, n)}{f(\epsilon, n)}=\frac{1}{2 n}-\frac{(\epsilon-p)^{2}}{2 p(1-p)}$ for the normal distribution of $\epsilon$ under MULT, (4) can be simplified by replacing the functions $u^{\prime}($.) and $u($.$) in the$ covariance terms with their second-order Taylor approximations around $\epsilon=p$, which gives ${ }^{11}$

$$
\begin{aligned}
0= & E U_{M U L T}^{\prime}\left(n^{* M U L T}\right) \\
& =E_{\epsilon}\left[u^{\prime}\left(I+n^{* M U L T} \epsilon-c\left(n^{* M U L T}\right)\right)\right] \\
& \cdot E_{\epsilon}\left[\left(\epsilon-c^{\prime}\left(n^{* M U L T}\right)\right)\right]+ \\
+ & \frac{1}{2} \cdot \operatorname{cov}_{\epsilon}\left[u^{\prime}\left(I+n^{* M U L T} \epsilon-c\left(n^{* M U L T}\right)\right),\right. \\
& \left.\epsilon-c^{\prime}\left(n^{* M U L T}\right)\right] .
\end{aligned}
$$

Alternatively, recalling Equation (2) and using the identity $\operatorname{cov}_{\epsilon}\left[u^{\prime}\left(I+n^{* M U L T} \epsilon-c\left(n^{* M U L T}\right)\right), \epsilon\right.$ $\left.-c^{\prime}\left(n^{* M U L T}\right)\right]=\int_{0}^{1} u^{\prime}\left(I+g\left(n^{* M U L T}, \epsilon\right)-c\left(n^{* M U L T}\right)\right)$ $(\epsilon-p) f\left(\epsilon, n^{* M U L T}\right) d \epsilon$, the same first-order condition (4a) can be rewritten as

$$
\text { (4b) } \begin{aligned}
0 & =E U_{M U L T}^{\prime}\left(n^{* M U L T}\right) \\
& =\int_{0}^{1} u^{\prime}\left(I+g\left(n^{* M U L T}, \epsilon\right)-c\left(n^{* M U L T}\right)\right)
\end{aligned}
$$

11. A second-order Taylor series expansion of $u^{\prime}(I+n €$ $-c(n))$ at $\epsilon=p$ gives $u^{\prime}(I+n \epsilon-c(n)) \approx u^{\prime}(I+n p-c(n))$ $+u^{\prime \prime}(I+n p-c(n)) \cdot n \cdot(\epsilon-p)+\frac{1}{2} u^{\prime \prime \prime}(I+n p-c(n)) \cdot n^{2}$. $(\epsilon-p)^{2}$, so that $A \equiv \operatorname{cov}_{\epsilon}\left[u^{\prime}(I+n \epsilon-c(n)), \epsilon-c^{\prime}(n)\right]=$ $u^{\prime \prime}(I+n p-c(n)) \cdot n \cdot \operatorname{var}(\epsilon-p)=u^{\prime \prime}(I+n p-c(n))(1-p) p$. The same procedure for $u(I+n \epsilon-c(n))$ renders $B \equiv$ $\operatorname{cov}_{\epsilon}\left[u(I+n \epsilon-c(n)) \frac{1}{2 n}-\frac{(\epsilon-p)^{2}}{2 p(1-p)}\right]=-\frac{1}{2 p(1-p)} \cdot \frac{1}{2} u^{\prime \prime}(I+$ $n p-c(n)) \cdot n^{2} \cdot \operatorname{var}(\epsilon-p)^{2}=-\frac{1}{2 p(1-p)} \cdot \frac{1}{2} u^{\prime \prime}(I+n p-$ $c(n)) \cdot n^{2} \cdot 2[\operatorname{var}(\epsilon-p)]^{2}=-\frac{1}{2} \cdot A$. Hence, $A+B=\frac{1}{2} \cdot A$. 


$$
\begin{aligned}
& \times\left(\frac{\epsilon+p}{2}-c^{\prime}\left(n^{* M U L T}\right)\right) \\
& \times f\left(\epsilon, n^{* M U L T}\right) d \epsilon .
\end{aligned}
$$

AON: all or nothing, in which $g(n, \epsilon)=\epsilon n$ as before, but now $\epsilon=1$ with probability $p$ and 0 otherwise. In this specification, the agent is facing progressively more noise than in MULT because the standard deviation of $\epsilon$ is larger, $\sqrt{p(1-p)}$ rather than $\sqrt{p(1-p) / n}$. In terms of the salesagent example, this specification means that all $n$ contacts that the agent makes will simultaneously succeed with probability $p$ or fail with probability $1-p$. Another example is a farmer who plants $n$ units of a crop, which will all flourish if the weather conditions turn out to be good, which will happen with probability $p$, or will all fail if conditions turn out to be bad, which will occur with probability $1-p$. As with MULT, the marginal product of effort under AON depends on the noise; however, the distribution of the noise term $\epsilon$ is not affected by effort. Accordingly, the first-order condition for optimal effort under $\mathrm{AON}$ is

$$
\begin{aligned}
0= & E U_{A O N}^{\prime}\left(n^{* A O N}\right) \\
= & p u^{\prime}\left(I+n^{* A O N}-c\left(n^{* A O N}\right)\right)\left(1-c^{\prime}\left(n^{* A O N}\right)\right) \\
& -(1-p) u^{\prime}\left(I-c\left(n^{* A O N}\right)\right) c^{\prime}\left(n^{* A O N}\right) .
\end{aligned}
$$

The application of our model to the cases above generates the following testable propositions (all proofs in Appendix 1).

PROPOSITION 1. The optimal effort choice under additive noise, $n^{* A D D}$, does not depend on the agent's risk attitude and is determined by the condition $p-c^{\prime}\left(n^{* A D D}\right)=0$.

PROPOSITION 2. The optimal effort under all or nothing, $n^{* A O N}$, is lower than that under multiplicative noise, $n^{* M U L T}$, which in turn is lower than that under additive noise, $n^{* A D D}$, for the risk averse: $n^{* A O N}<n^{* M U L T}<n^{* A D D}$. For the risk loving, the opposite is true: $n^{* A D D}<n^{* M U L T}<n^{* A O N}$. For the risk neutral, the optimal effort is the same under all specifications for the noise in the production function so that $n^{* A O N}=n^{* M U L T}=n^{* A D D}$, and is determined from $p-c^{\prime}(n)=0$.

PROPOSITION 3. The optimal effort levels under multiplicative noise, $n^{* M U L T}$, and all or nothing, $n^{* A O N}$, both decrease with risk aversion.
PROPOSITION 4. The difference between optimal effort levels under MULT and AON increases with risk aversion.

PROPOSITION 5. The variance of individual effort choices increases from $A D D$ to $M U L T$ to $A O N$ : $\operatorname{var}\left(n^{* A O N}\right)>\operatorname{var}\left(n^{* M U L T}\right)>\operatorname{var}\left(n^{* A D D}\right)=0$.

REMARK 1. How dependent are our theoretical predictions on the assumption that effort is measurable in monetary terms so that utility is nonseparable in output and costs of effort, and can be written as $u(I+g(n, \epsilon)-c(n))$ ? Proposition 1 - effort under ADD being independent of risk preferences-requires this assumption because otherwise marginal utility, and hence risk considerations, would be included in the first-order condition for effort. In our experiment, where "effort" and rewards are both denominated in monetary units, this nonseparable utility function is appropriate. This assumption coupled with the assumption of a linear compensation contract and additive noise corresponds to the canonical linear agency model as discussed by Sloof and van Praag (2008). The first part of Proposition 2-effort under MULT is lower than under ADD for the risk averse-holds under separable utility functions if the distributions of the multiplicative and additive noise are the same. ${ }^{12}$ None of the other propositions require that the costs of effort be measurable in monetary terms or that the utility function be nonseparable in output and effort costs. This is because the cost of effort function neither includes nor interacts with the noise and can thus be taken out of the covariance or integral operators in the expressions underlying the proofs of our propositions without changing the signs of these expressions.

12. Take any point $n_{0}$ and fix the distributions of the additive and multiplicative noise to be the same at $n_{0}$. Then, the expected utility net of costs of effort under ADD is $E U_{A D D}(n)=\int_{0}^{1} u\left(I+p n+n_{0}(\epsilon-p)\right) f(\epsilon) d \epsilon-c(n) . \quad$ The expected marginal net utility taken at $n_{0}$ is $E U_{A D D}^{\prime}\left(n_{0}\right)=$ $\int_{0}^{1} u^{\prime}\left(I+n_{0} \epsilon\right) p f(\epsilon) d \epsilon-c^{\prime}\left(n_{0}\right)$. The expected net utility under MULT is $E U_{M U L T}(n)=\int_{0}^{1} u(I+n \epsilon) f(\epsilon) d \epsilon-c(n)$, and the expected marginal net utility taken at $n_{0}$ is $E U_{M U L T}^{\prime}\left(n_{0}\right)=$ $\int_{0}^{1} u^{\prime}\left(I+n_{0} \epsilon\right)\left(\frac{\epsilon+p}{2}\right) f(\epsilon) d \epsilon-c^{\prime}\left(n_{0}\right) \quad$ (recall Equation 4b). The difference $E U_{M U L T}^{\prime}\left(n_{0}\right)-E U_{A D D}^{\prime}\left(n_{0}\right)=\int_{0}^{1} u^{\prime}(I+$ $\left.n_{0} \epsilon\right)\left(\frac{\epsilon-p}{2}\right) f(\epsilon) d \epsilon=\operatorname{cov}\left(u^{\prime}\left(I+n_{0} \epsilon\right) \frac{\epsilon-p}{2}\right)$, is negative for the risk averse because $u^{\prime}\left(I+n_{0} \epsilon\right)$ decreases, whereas $\frac{\epsilon-p}{2}$ increases, with $\epsilon$. Hence, the optimal effort under MULT is always lower than under ADD for the risk averse even under separable utility. 
Hence, the effects of risk preferences on effort under MULT and AON do not hinge on either the measurability assumption or on nonseparability.

REMARK 2. Throughout our analysis so far, we have assumed an interior solution for $\mathrm{n}$. The comparative statics behind our theoretical propositions would of course fail in the case of a corner solution. Corner solutions are theoretically possible. Continuing with the sales-agent example, the required number of customer contacts may be so high that all agents irrespective of risk preferences would just meet this minimum. Alternatively, cultivating customer contacts may be so (surely) rewarding that all the available time would be spent on this activity. In our experiment (next section), we calibrated the payments to try to avoid either upper or lower corner solutions. There are very few choices corresponding to the corner solutions, and removing these observations does not affect our results.

Mean-Variance Intuition: We now provide some intuition for our propositions using the mean-variance framework in which the mean and variance of the payoff distribution are the only two parameters that affect decisions under risk. Conveniently, this framework allows to express income risk as payoff variance, and the disutility of risk as a monotonic function of payoff variance with a risk-aversion parameter. Useful though this simplification is for illustration purposes, our propositions do not rely on it and are applicable beyond the mean-variance framework, that is, in situations where decisions under risk are affected by higher moments of the payoff distribution with the caveats outlined above.

All our propositions follow from the fact that different specifications of noise in the production function imply different relationships between effort and disutility of risk, and hence different possibilities for achieving the optimal trade-off between expected income and income risk through optimal effort choice. Recall that the variance, representing disutility of risk, is not affected by effort under ADD, increases with effort under MULT (in which case the payoff variance is $n p[1-p]$ ), and does so even more steeply under AON (the payoff variance is $\left.n^{2} p(1-p)\right)$. Since the variance or disutility of risk is independent of effort under ADD, all risk types will choose the same level of effort, maximizing the expected payoff (Proposition 1). Higher effort, by increasing the variance or disutility of risk under MULT and AON, encourages the risk averse to trade-off some expected income in exchange for less income risk. As the utility gains from bearing less risk increase with the degree of risk aversion, while the opportunity costs in terms of lower expected income stay the same, more risk-averse individuals will trade-off more expected income by choosing lower effort than less risk-averse individuals in the same situation (Proposition 3). As the opportunity costs of choosing lower effort are the same under MULT and AON while the gains in terms of lower disutility of risk are higher under AON (where income risk is more strongly affected by effort) than MULT, a given risk-averse individual will choose a lower effort level under AON than under MULT (Proposition 2), and increasingly so with the degree of risk aversion (Proposition 4). As effort affects income risk progressively more strongly as one moves from ADD to MULT to $\mathrm{AON}$, the same distribution of risk preferences will generate a greater variety of optimal effort choices under AON than under MULT and under ADD (Proposition 5).

\section{EXPERIMENT}

\section{A. Menu-Based Effort Selection Versus Real Effort}

All three experiments with multiplicative noise (Cadsby, Song, and Tapon 2007, 2016; Zubanov 2015) that demonstrated an inverse relationship between risk aversion and effort under linear incentives use a real-effort task. Asking participants to exert real effort has the important advantage of verisimilitude. However, the real-effort design also leads to some confounds and difficulties in interpretation.

First, while the opportunity cost of effort can be controlled by means of an alternative task with a positive value in a real-effort design, any direct impact on utility arising from either enjoyment or dislike of either the main or the alternative task is impossible to control or even directly observe. Such psychological effects on utility will generally differ from person to person not just in magnitude but also in direction since some may derive pleasure from performing a task while others find it burdensome. Not being able either to control or to observe the psychological impact of effort on task utility adds a great deal of noise to any attempt at ascertaining the relationship between effort and incentives for participants with differing risk attitudes. If there were 
an unobservable but systematic link between risk attitude and the psychological effect of effort expended on the task, the implications of an apparent observed relationship between risk attitude and effort-based performance could be misinterpreted. For example, with real effort, such a relationship could be present as an artifact of the unobserved link even in our additive case seemingly but misleadingly appearing to contradict the predictions of theory.

Second, in real-effort experiments, we can generally observe performance, which is the result of effort. However, it is more difficult to measure the level of effort accurately. For example, while the number of attempts at a task can be measured and used to represent effort, it is often unclear how focused and serious a participant's attempts actually were. Focus and seriousness, while clearly an aspect of effort, are thus not captured by simple tallies of the number of attempts at a task. For this reason, performance is often used as a proxy for effort. However, this is also problematic because the relationship between effort and performance may itself be affected by a participant's attitude toward financial risk through choking under pressure.

Choking under pressure arises from an element of anxiety that may affect observed performance under incentive pay. When a participant is paid a fixed salary, he or she does not have to worry about financial uncertainty since the payoff of each participant is predetermined and independent of performance. However, under a pay-for-performance scheme, financial uncertainty becomes a potentially important concern because pay is now uncertain and contingent on performance, which is a product of effort and the probability of success. A more risk-averse participant is by definition a person who dislikes financial uncertainty. Such a person may therefore feel uncomfortable in the financially uncertain pay-for-performance environment. This discomfort may result in choking under pressure, such that despite his or her best efforts, a person may choke and thus perform poorly (Ariely et al. 2009; Baumeister 1984; Baumeister and Showers 1986; Cadsby, Song, and Tapon 2007, 2016). In contrast, a risk-tolerant person might thrive in such an environment. Thus, in a real-effort experiment, it is very difficult to identify whether an observed inverse relationship between risk aversion and performance responsiveness to incentives is due to the hypothesized inverse relationship between risk aversion and effort, to a relationship between risk aversion and choking under pressure, or to both. Again this could give rise to a misleading apparent empirical relationship between risk aversion and performance responsiveness even in the additive case reflecting choking under pressure even though theory predicts no such relationship between risk aversion and effort in the additive case.

In order to avoid these confounds and focus on the proposed direct relationship between risk attitude and effort, we perform a laboratory experiment that eschews real effort in favor of a menu-based effort-selection design (e.g., Bull, Schotter, and Weigelt 1987; Fehr, Kirchsteiger, and Riedl 1993). The menu specifies the same cost-of-effort function for all participants, thereby avoiding the problems that arise when this cost is not transparent to the researcher. Since participants select costly effort without having to actually perform, their effort choices are directly observable and not confounded with potential choking. The results of the experiment will shed light on the relationship between risk aversion and the performance response to incentives previously observed in the cited realeffort experiments. If the hypothesized inverse relationship between risk aversion and effort is empirically corroborated, such a relationship likely underlies at least in part the relationship between risk aversion and performance observed in the real-effort environment. If in contrast no such relationship is found in our menu-based effort-selection experiment, it is likely that the observed relationship in the real-effort context was due to choking under pressure or an unobserved relationship between individual risk attitudes and the cost of effort. Thus, this menu-based effort design should be viewed as an attempt to clarify the mechanism underlying the results of the earlier real-effort experiments, which have already demonstrated the existence of a significant inverse relationship between risk aversion and real effort.

\section{B. Experimental Procedures}

The experiment was run at Zhejiang University in Hangzhou, China. Participants were recruited by posting an announcement on an electronic university bulletin board. A total of 180 undergraduate and graduate students from various majors participated in the study. There were 64 males and 116 females with an average age of 21.90 years. The experiment was programmed and conducted using z-Tree software (Fischbacher 2007). Each experimental session 
lasted about an hour, and the average earnings were 34.2 RMB for each participant inclusive of a 5 RMB show-up fee. ${ }^{13}$ The average hourly student wage for a part-time job was about $20 \mathrm{RMB}$ at Zhejiang University at the time of the experiment. Thus, the earnings were salient and attractive to our participants.

To compare the behavioral responses of each participant in a noiseless control treatment with their responses to the additive, multiplicative and all-or-nothing treatments, we adopted a withinperson design. Specifically, there was a control treatment with no noise and three contrasting experimental treatments: additive noise, multiplicative noise, and all-or-nothing noise. Every participant went through all four treatments in a single session, each of which was administered in a separate decision period of about 10 minutes. In each period, all participants were endowed with a sum of 100 ECUs, with $1 \mathrm{ECU}=0.20 \mathrm{RMB}$, and their task was to decide how much of that endowment to invest in certificates that would earn them income in the manner specified for that period. The total cost (TC) of investment was an increasing function of the number of certificates purchased $(n)$, specifically TC $=0.5 n^{2}$. Thus, the unit cost (UC) of a certificate also increased with the number of certificates purchased, since $\mathrm{UC}=0.5 n$. Participants were given not only the cost function itself, but also a table delineating both the per-unit and TCs corresponding to the number of certificates purchased from 0 to 14 .

The rules determining income from investment differed by treatment, and were explained in the written instructions presented just prior to the period in which the treatment was administered. ${ }^{14}$ After reading the instructions for each period, participants answered two numerical quiz questions to ensure that they understood the instructions correctly. To minimize various possible confounds that are often associated with within-person experimental designs we implemented the following procedures. First, to avoid wealth effects, the outcomes of earlier periods were neither realized nor communicated to participants until all periods were completed. Second, at the end of the experiment only one of the four decision periods was chosen at random for payment. Third, to control for possible learning effects, we randomly matched each of the

13. At the time of the experiment, $34.2 \mathrm{RMB}$ was equal to about $\$ 5.56$.

14. All instructions used are included in the supplementary material. six possible orderings of the three experimental treatments to one of six separate sessions. The control treatment was always administered first. There were exactly 30 subjects in each session. In all four treatments, purchasing ten certificates maximizes the expected monetary payoff. Thus, a risk-neutral agent would buy ten certificates under all four treatments.

For the Control treatment (denoted CON in what follows), participants were instructed as follows: "For each certificate you purchase, you will receive 10 ECUs in revenue. Thus, your total earnings in this period will be calculated as follows: Total Earnings $=$ Endowment + Total Revenue - Total Cost $=100+(10 \times n)-n \times$ $(0.5 \times n)$, where $n=$ the number of certificates purchased."

For the Additive Noise treatment (denoted ADD), participants were told: "For each certificate you purchase, you will receive 10 ECUs in revenue in this period. Thus, your provisional earnings in this period will be calculated as follows: Provisional Total Earnings $=$ Endowment + Total Revenue - Total Cost $=100+(10 \times n)-n$ $\times(0.5 \times n)$, where $n=$ the number of certificates purchased. A random process will then determine whether your provisional earnings will be 1) reduced by 31.6 ECUs, or 2) increased by 31.6 ECUs, with both outcomes having equal probability. Think of the random process as the outcome of a fair coin toss for which your Final Total Earnings equal your Provisional Earnings - 31.6 ECUs if the outcome is a head and your Final Total Earnings equal your Provisional Earnings +31.6 ECUs if the outcome is a tail." The additive noise value of 31.6 ECUs was selected so that the variance of the additive noise process would equal the variance of the multiplicative noise process at $n=10$, the optimal number of certificates for a risk-neutral agent maximizing his/her expected payoff in the multiplicative noise treatment.

For the Multiplicative Noise treatment (denoted MULT), participants were informed: "For each certificate you purchase, you will receive either 20 or 0 ECUs in revenue with equal probability in this period. Think of the revenue from each certificate as the outcome of a fair coin toss for which the revenue will be 20 ECUs if the outcome is a head, and 0 ECUs if the outcome is a tail. Note that the revenue outcome for each individual certificate does not in any way depend on the outcome for any other certificate. This means that whether you receive 20 or 0 ECUs for one of your certificates has 
no bearing on whether you will receive 20 or 0 ECUs for any of the other certificates you purchase. Suppose that you purchase $n$ certificates. Of those, suppose it turns out that you earn 20 ECUs for $s$ certificates and 0 ECUs for the remainder. Then your earnings will be calculated as follows: Total Earnings $=$ Endowment + Total Revenue - Total Cost $=100+(20 \times s)-n \times$ $(0.5 \times n) . "$

For the All-or-Nothing treatment (denoted AON), we told the participants: "For all the certificates you purchase, you will receive either 20 or 0 ECUs per certificate in revenue with equal probability in this period. Think of the revenue as the outcome of a fair coin toss for which you will receive 20 ECUs times the number of certificates purchased as revenue if it is a head, and 0 ECUs if it is a tail. Suppose that you purchase $n$ certificates. Then your earnings will be calculated as follows: Total Earnings $=$ Endowment + Total Revenue - Total Cost $=100+[(20 \times n)$ OR 0 with equal probability] $-n \times(0.5 \times n)$."

At the end of the experiment, we collected demographic information such as gender, age, and study major from all participants. In addition, we measured each participant's WTR as the response to the following question: "How do you see yourself: are you generally a person who is fully prepared to take risks or do you try to avoid taking risks? Please tick a box on the scale 0 (not at all willing to take risks) to 10 (very willing to take risks)." The response to this question has been used as a measure of risk aversion, and has been found to correlate reliably with behavior involving risk in real and incentivized situations (Dohmen et al. 2011; Gibson and Johnson 2018; Lönnqvist et al. 2015). We chose this unincentivized attitudinal measure over an incentivized behavioral elicitation of risk for two reasons. First, the experimental treatments themselves elicit behavior toward different forms of risk in much the same way as do common incentivized elicitations of risk. Using one such incentivized measure either immediately before or immediately after the main experimental decision might have identified those behaving in a risk-averse, risk-loving, or risk-neutral manner during the experiment as having the corresponding preferences merely through a desire to exhibit consistency. We believe it is more interesting and informative as a more challenging robustness check on the incentivized behavior and attitudes exhibited when performing the experimental task itself to compare the decisions toward risk revealed in the experiment with risk attitudes elicited by an entirely different albeit unincentivized method rather than comparing two sets of incentivized decisions made in a very similar context. Second, Lönnqvist et al. (2015) compare the incentivized lottery-choice risk elicitation method developed by Holt and Laury (2002) with the unincentivized questionnaire elicitation method used by Dohmen et al. (2011) from which we took our question. They find only very weak correlation between the two risk measures. Moreover, the questionnaire-based method gives stable results over time when readministered on the same subjects after 1 year, while the lottery-based procedure does not. While the questionnaire-based method exhibits predicted correlations with the Big Five Personality measure, the lottery-based measure fails to do so. Finally, the questionnaire-based method is correlated with risk-taking behavior in a standard trust game (Berg, Dickhaut, and McCabe 1995), while the lottery-based measure is not. While not drawing any general conclusion about the superiority of one measure over the other, we decided for these two reasons that the unincentivized question would be most appropriate in our experimental setting.

\section{RESULTS}

Table 1 reports descriptive statistics by treatment separately for each of the six ordering sequences, and in aggregate. It also reports analogous results for responses to the question concerning WTR. In the last column of Table $1, F$-tests of equality of means indicate that neither the average number of certificates purchased in a given treatment nor the mean participant-reported WTR varies significantly by the ordering of the treatments. Nonparametric Kruskal-Wallis tests yield qualitatively identical results. ${ }^{15}$ We therefore pool the data from the different sessions for analysis. Figure 2 displays the distribution of the number of certificates purchased by treatment. We focus first on the $\mathrm{CON}$ treatment for which the profit-maximizing choice is to purchase 10 certificates regardless of risk preferences. It is reassuring that $n=10$ was chosen by 163 out of 180 participants, $90.6 \%$ of the total. The mean number of certificates purchased by all 180 participants was equal

15. We also performed Kolmogorov-Smirnov tests on each pair of sequences. In no case could we reject the null hypothesis that the pair of sequences comes from the same underlying distribution. 
TABLE 1

Descriptive Statistics

\begin{tabular}{|c|c|c|c|c|c|c|c|c|c|}
\hline \multirow[b]{2}{*}{$\begin{array}{l}\text { Number of Certificates } \\
\text { Purchased }(n) \text { : }\end{array}$} & \multicolumn{2}{|c|}{ Overall } & \multicolumn{7}{|c|}{ Means by Treatment Sequence } \\
\hline & Mean & Variance & 1 & 2 & 3 & 4 & 5 & 6 & $\begin{array}{c}t \text {-Tests of Equal } \\
\text { Means } \\
p \text { Value }\end{array}$ \\
\hline CON: no noise & 9.844 & 1.157 & 9.800 & 9.967 & 9.655 & 10.129 & 9.800 & 9.700 & 0.378 \\
\hline ADD: additive noise & 9.689 & 1.705 & 9.667 & 9.800 & 10.000 & 9.645 & 9.533 & 9.500 & 0.634 \\
\hline MULT: multiplicative noise & 9.472 & 2.955 & 9.100 & 9.967 & 9.379 & 9.774 & 9.400 & 9.200 & 0.852 \\
\hline AON: all or nothing & 7.561 & 3.913 & 7.267 & 8.200 & 8.103 & 6.355 & 7.667 & 7.833 & 0.413 \\
\hline $\begin{array}{l}\text { Self-reported willingness to take risks } \\
(0=\text { not willing, } 10=\text { very willing })\end{array}$ & 5.839 & 2.128 & 5.333 & 6.467 & 5.621 & 5.290 & 6.233 & 6.100 & 0.156 \\
\hline
\end{tabular}

FIGURE 2

Distribution of the Number of Certificates Purchased by Treatment
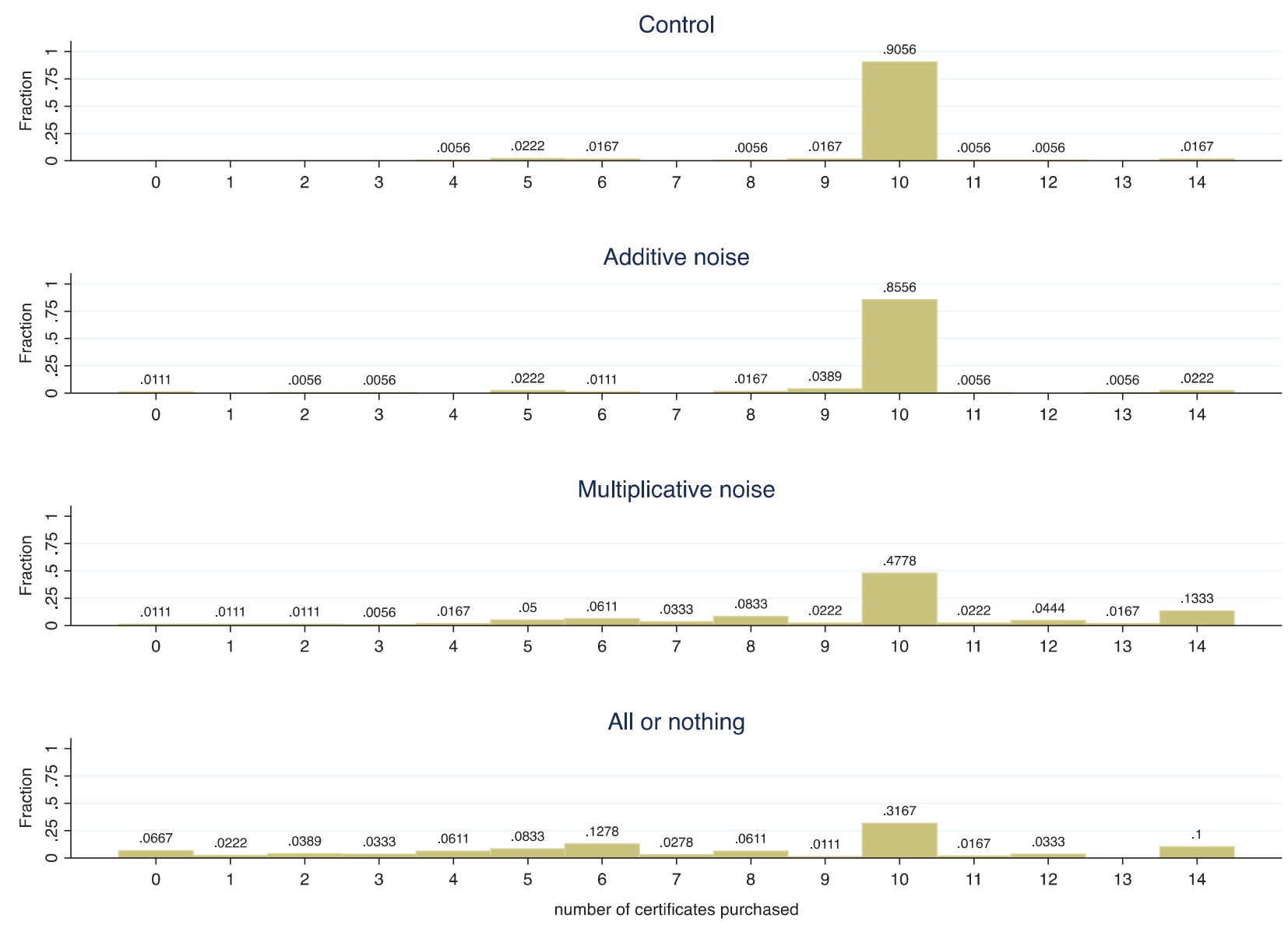

to 9.844 , which a $t$-test reveals to be not significantly different from 10 . We now proceed to discuss the rest of the results, numbered to correspond with the theoretical propositions.

RESULT 1. The number of certificates purchased (effort) under ADD is independent of individual risk attitudes and not significantly different from 10, which maximizes both the expected monetary payoff and expected utility.
154 participants, representing $85.6 \%$ of the total, purchased ten certificates under ADD. A $t$-test reveals that the mean number of 9.689 certificates purchased under ADD does not differ significantly from 10 . The first two columns of Table 2 report regression results for the ADD treatment. Our focal explanatory variable is WTR. In column 1, WTR is the sole explanatory variable. In column 2 , to check the robustness of our results, we add age, gender, major, and 
TABLE 2

Regression Results of Certificates Purchased on Willingness to Take Risks and Controls

\begin{tabular}{|c|c|c|c|c|c|c|c|c|}
\hline & $\begin{array}{c}\text { ADD } \\
\text { (1) }\end{array}$ & $\begin{array}{l}\text { ADD } \\
\text { (2) }\end{array}$ & $\begin{array}{l}\text { MULT } \\
\text { (3) }\end{array}$ & $\begin{array}{l}\text { MULT } \\
\text { (4) }\end{array}$ & $\underset{(5)}{\mathrm{AON}}$ & $\begin{array}{c}\mathrm{AON} \\
\text { (6) }\end{array}$ & $\underset{\text { (7) }}{\text { MULT-AON }}$ & $\underset{(8)}{\text { MULT-AON }}$ \\
\hline $\begin{array}{l}\text { Willingness to } \\
\text { take risks }\end{array}$ & $\begin{array}{c}0.030 \\
(0.043)\end{array}$ & $\begin{array}{c}0.024 \\
(0.042)\end{array}$ & $\begin{array}{c}0.377 * * * \\
(0.115)\end{array}$ & $\begin{array}{c}0.424 * * * \\
(0.113)\end{array}$ & $\begin{array}{c}0.947 * * * \\
(0.107)\end{array}$ & $\begin{array}{c}0.915 * * * \\
(0.115)\end{array}$ & $\begin{array}{c}-0.568 * * * \\
(0.147)\end{array}$ & $\begin{array}{c}-0.491 * * * \\
(0.153)\end{array}$ \\
\hline Age & & $\begin{array}{l}-0.131 \\
(0.010)\end{array}$ & & $\begin{array}{l}-0.053 \\
(0.110)\end{array}$ & & $\begin{array}{l}-0.034 \\
(0.132)\end{array}$ & & $\begin{array}{l}-0.019 \\
(0.163)\end{array}$ \\
\hline Male & & $\begin{array}{c}0.334 \\
(0.229)\end{array}$ & & $\begin{array}{c}0.718 \\
(0.486)\end{array}$ & & $\begin{array}{l}1.645^{* * *} \\
(0.592)\end{array}$ & & $\begin{array}{l}-0.927 \\
(0.697)\end{array}$ \\
\hline Major & no & yes & no & yes & no & yes & no & yes \\
\hline $\begin{array}{l}\text { Treatment } \\
\text { sequence }\end{array}$ & no & yes & no & yes & no & yes & no & yes \\
\hline
\end{tabular}

Notes: 180 obs. Robust standard errors are in parentheses. $* * *$ Significance at the $1 \%$; and $* *$ significant at $5 \%$.

treatment sequence as controls. Age is entered as the reported age of the participant, gender is specified as a dummy variable, a series of four dummy variables are used to indicate five broad categories of major (biology and medical, arts, science, social science, and other majors) and five dummies are used for the different treatment sequences. In neither regression is WTR significantly related to the number of certificates purchased. None of the controls matter either.

RESULT 2. Of the 163 participants who purchase ten certificates under CON as predicted, $117(71.8 \%)$ exhibit behavior consistent with our model. Specifically, $30(18.4 \%)$ exhibit consistent risk-neutral behavior, 65 (39.9\%) exhibit consistent risk-averse behavior, and 22 (13.5\%) exhibit consistent risk-loving behavior in accordance with Propositions 1 and 2.

Proposition 2 was derived using a continuous function for exertion of effort. In the experiment, effort was represented by a discrete choice variable: the integer number of certificates purchased. The model predictions, adapted for the discrete nature of the choices made by the participants in our laboratory environment are as follows: A risk-neutral participant will maximize expected earnings by purchasing ten certificates regardless of treatment, that is, under ADD, MULT, and AON. Thus, risk neutrality implies $n^{* \mathrm{AON}}=n^{* \mathrm{MULT}}=n^{* \mathrm{ADD}}=10$. $\mathrm{A}$ slightly risk-averse or slightly risk-loving participant might make identical choices because it is not permitted to purchase fractional numbers of certificates. For convenience, we categorize all participants exhibiting such behavior as risk neutral. For a risk-averse participant, $n^{* \mathrm{AON}} \leq n^{* \mathrm{MULT}} \leq n^{* \mathrm{ADD}}=10$. For a sufficiently risk-averse participant, at least one of these inequalities will be strict, and for convenience we require this to categorize a participant as risk averse. Analogously, for a risk-loving participant, $n^{* \mathrm{AON}} \geq n^{* \mathrm{MULT}} \geq n^{* \mathrm{ADD}}=10$ with at least one strict inequality required to be classified as risk loving under our categorization. Of those behaving in accordance with the predictions of our model, it is not surprising to find the majority of participants exhibit risk-averse behavior, consistent with many other studies (e.g., Binswanger 1980; Holt and Laury 2002).

The distributions of the WTR scores differ by revealed risk preference type. Participants exhibiting revealed risk aversion/risk loving behavior have lower/higher average WTR scores than risk-neutral ones. The revealed risk preference types are correlated, albeit imperfectly, to the reported WTR scores. Figure 3 shows the distributions of the WTR score by revealed risk preference type. Compared to the entire sample, the WTR distribution for the risk neutral is truncated at both tails. Thus, there are no participants claiming to be extremely risk loving or risk averse among the revealed risk neutral. There is an overall shift to the left in the WTR distribution for the risk averse who tend to claim lower WTR, and to the right for the risk loving who correspondingly tend to claim a greater WTR. The Kolmogorov-Smirnov test for equality of two distributions rejects the hypothesis that WTR distributions of the risk averse and risk loving are the same at $p<0.001$. The same test applied to compare the WTR distributions for risk neutral and risk averse, and for risk neutral and risk loving, gives $p$ values of 0.314 and 0.001 respectively. The mean WTR differs significantly 
FIGURE 3

Distribution of the Willingness to Take Risks (WTR) by Revealed Risk Preference Type
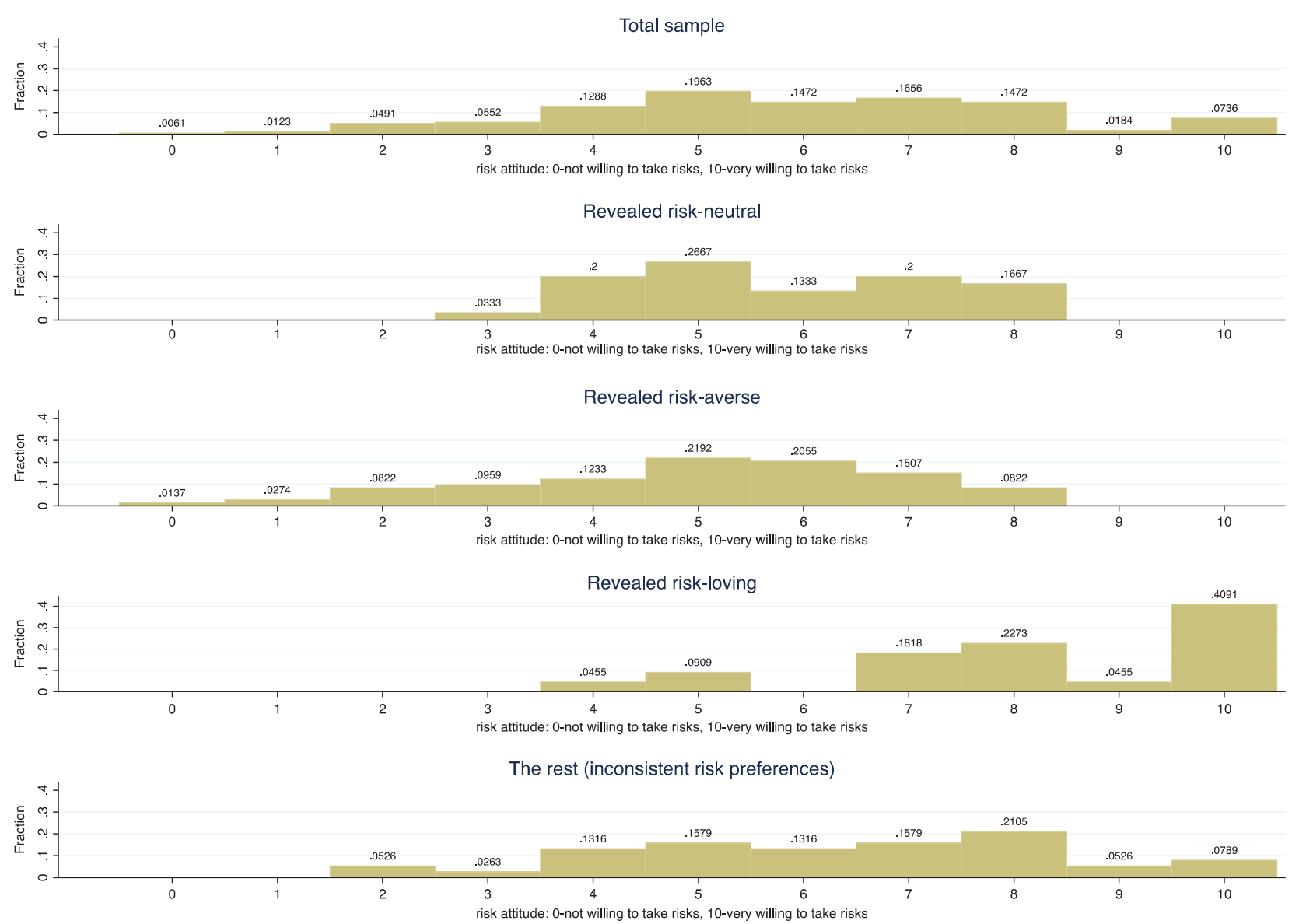

by type: 5.77 for risk neutral, 4.96 for risk averse, and 8.23 for risk loving, while the equal mean test yields $F=25.7$ with $p<0.001$.

RESULT 3. The number of certificates purchased ( $=$ our experimental effort) under both MULT and AON increases with WTR, and hence decreases with risk aversion.

The third and fourth columns of Table 2 report regression results for the MULT treatment. In column 3, WTR is the sole explanatory variable. In column 4, to check the robustness of our results, we add age, gender, major, and treatment sequence as controls. In both cases, the coefficient on WTR is positive and significant at the $1 \%$ level as predicted by Proposition 3 . None of the controls is significant.

The fifth and sixth columns of Table 2 report analogous regression results for the AON treatment. Once again, the coefficient on WTR is positive and significant at the $1 \%$ level both with and without controls. The gender control is significant at the 5\% level, indicating that males on average purchase significantly more certificates than equally risk-averse or risk-loving females.

RESULT 4. The difference between the number of certificates purchased under MULT and the number purchased under AON decreases with WTR, and hence increases with risk aversion.

The seventh and eighth columns of Table 2 report regression results using MULT-AON as the dependent variable with and without controls, respectively. In both cases, this difference decreases with WTR, which is significant at the $1 \%$ level.

RESULT 5. The variance of the numbers of certificates purchased in the AON treatment is significantly greater than the variance in the MULT treatment, and the variance in the MULT treatment is significantly greater than the variance in the ADD treatment as predicted. However, the 
variance in the $A D D$ treatment is $1.705>0$ contrary to Proposition 5.

The variances for the number of certificates purchased under each treatment are presented in Table 1. A two-sample variance-comparison test indicates that the variance of 3.913 in the AON treatment is significantly different from the lower variance of 2.955 in the MULT treatment $(p<0.001)$. Moreover, the variance in the MULT treatment is significantly different from the lower variance of 1.705 in the ADD treatment $(p<0.001)$. Levene's robust test statistic leads to identical conclusions. The variance in the ADD treatment is not equal to zero as predicted by Proposition 5 because of the 26 out of 180 participants who did not purchase 10 certificates as predicted by Proposition 1.

\section{DISCUSSION}

\section{A. Loss Aversion as an Alternative Explanation to Our Findings}

Our findings may have been driven by loss aversion (possible losses looming larger than possible gains) as well as risk aversion (an equal dislike of uncertainty in losses or gains). These two attitudes, while different, are clearly related. Indeed, our measure of risk aversion, the WTR, may have picked up loss aversion as well as risk aversion proper (as in Koudstaal, Sloof, and van Praag 2016). Hence, the correlations between WTR and the number of certificates purchased by treatment that we report in Table 2 may in fact be due to a disutility from losses that is stronger than the utility from comparable gains rather than to uncertainty in general.

An attempt to separate the effects of loss aversion from those of risk aversion on participants' choices in our study would have necessitated two additions to the existing experimental design. First, we would have had to elicit the participants' reference points for calculating gains and losses (the initial endowment and expected payoff are likely reference points). Then, we would have needed to create, for each condition, a pair of treatments in which the payoff distributions have the same expected value and risk but differ in the likelihood of a loss relative to the reference point (as in Brooks and Zank 2005, for instance); the former is required to control for the effect of risk aversion, the latter to examine the potential effects of loss aversion. This would have been a more complicated design which would have required a much larger sample to provide sufficient power, especially given a substantial correlation between loss and risk aversion and the behaviors they generate, and was therefore left for future research.

Assuming our results are driven entirely by loss aversion, could they still be reconciled with our theoretical predictions, which are developed based on risk aversion? It turns out that our model, when respecified with a utility function with loss aversion alone, generates the same predictions for all treatments as those from our original model (see Appendix 2). Therefore, the general message of our study is even more broadly applicable: effort choices are a behavior toward uncertainty (risk or loss) to the extent that they affect the distribution of possible outcomes. We explore the implications in what follows.

\section{B. Implications of Our Results}

Rooted in workers' utility functions and the methods firms use to measure and reward performance, the relationship between risk or loss aversion and effort is likely to be enduring and important for management practice for two reasons. First, multiplicative noise, under which this relationship holds, occurs whenever the marginal product of effort is uncertain at the time of effort choice. Examples of such situations are many and include effort spent on research and development of new technologies and products, effort spent on marketing campaigns as well as the sales agent example used to motivate this study. ${ }^{16}$

Second, linking our study with the related literature on background risk (Beaud and Willinger 2015; Gollier and Pratt 1996) suggests that additive background risk may amplify the effect of multiplicative noise on effort. In real-world settings, many workers making effort choices face such background risk. Consider an environment that exposes an employee to both additive background risk and multiplicative or all-or-nothing risk that increases with his/her choice of effort level. An increase in additive background risk in the presence of multiplicative or all-or-nothing risk will increase absolute risk aversion, thereby causing the risk vulnerable to reduce their effort. Similarly, multiplicative or all-or-nothing risk

16. An interesting enrichment to our sales agent story, left for future research, is to endogenize the probability of a successful contact by making it a function of effort. Then, one would have a model with two-dimensional effort in which more risk-averse agents make fewer contacts but exert more effort cultivating each contact they do make. 
would have a stronger effect on the effort exerted by the risk vulnerable when they are already experiencing uncontrollable additive risk.

Since it is the result rather than effort per se that is often rewarded, it is vital that incentive compensation schemes reflect the link between risk aversion and effort. There are several practical alternatives to the linear output-based incentives under multiplicative noise considered in this study. One is to reward input as well as output - a solution proposed in Raith (2008), though for a risk-neutral rather than a risk-averse agent. In our example, this means paying the sales agent per customer contact as well as per successful transaction. When the probability of a deal is independent of effort, paying a risk-averse agent per contact is an improvement over paying per successful transaction because it removes all risks from the agent's pay. However, when the probability of a successful outcome does depend on effort, paying per contact will lead to all effort being spent on making new contacts and none on cultivating existing ones. An element of pay per successful transaction would therefore be required as part of total compensation, bringing the negative risk aversion-effort link back to the fore.

Another alternative is to offer convex outputbased incentives, whereby the agent's pay grows faster than his/her output to compensate for the increasing costs of bearing multiplicative risk. However, such convex incentives may encourage excessive risk taking by less risk-averse agents, in much the same way as they have done in the hedge fund industry (de Figueiredo, Rawley, and Shelef 2013). An alternative to globally convex incentives are locally convex ones, which encourage extra effort from the risk-averse agents who would otherwise have chosen low effort while not giving extra incentive for risk taking to the harder-working, less risk-averse agents. A typical example of locally convex incentives is a target bonus paid on top of usual earnings once output reaches the target-a scheme examined in Zubanov (2015). Our work helps to understand why such locally convex incentive schemes exist and suggests that their parameters should take account of the relationship between effort and performance as well as risk preferences.

\section{CONCLUSION}

Allocation of time between risky effort and risk-free leisure under a given pay-forperformance scheme may be affected by risk preferences. Our model delineates the conditions under which this occurs. In particular, we show that if financial uncertainty increases with the amount of effort, as in the multiplicative noise and all-or-nothing treatments, risk-averse individuals will choose less effort and accept a lower expected return to mitigate risk, while risk-loving individuals will choose more effort, accepting greater risk and a lower expected return in pursuit of the chance of a large payoff. We also show that when financial uncertainty is not affected by effort, as in the additive noise treatment, risk preferences do not affect effort choices.

In our experiment, of the 163 participants who make the payoff-maximizing choice in a no-noise control treatment, $71.8 \%$ make decisions consistent with the predictions of our model in all three experimental treatments. Specifically, $39.9 \%$ are consistently risk averse, $13.5 \%$ are consistently risk loving, and $18.4 \%$ are consistently risk neutral. These consistency results provide strong support for our model, and are independent of our questionnaire-based willingness-to-take-risks measure. They demonstrate that effort selection decisions in the face of multiplicative or all-or-nothing risk, both of which increase with effort, may be thought of as analogous to the decision of an investor choosing the proportion of wealth to hold in a safe asset versus a risky portfolio. This is because conservation of costly effort has a safe and certain return, while exerting more effort produces an increasingly uncertain payoff. The strong corroboration of an inverse relationship between risk aversion and effort under both multiplicative and all-or-nothing noise suggests that such a relationship is an important mediating component of the previously observed inverse relationship between risk aversion and the performance response to incentives in the real-effort case (e.g., Cadsby, Song, and Tapon 2016, and the example in the Introduction). Researchers studying heterogeneous responses to incentives, as well as practitioners designing workforce compensation schemes, should take notice.

\section{APPENDIX A: PROOFS OF PROPOSITIONS 1-5}

PROPOSITION 1. The optimal effort choice under additive noise, $n^{* A D D}$, does not depend on the agent's risk attitude and is determined by the condition $p-c^{\prime}\left(n^{* A D D}\right)=0$.

The proof follows immediately from the first-order condition (3). 
PROPOSITION 2. The optimal effort under all or nothing, $\mathrm{n}^{* \mathrm{AON}}$, is lower than that under multiplicative noise, $\mathrm{n}^{* \mathrm{MULT}}$, which in turn is lower than that under additive noise, $\mathrm{n}^{* \mathrm{ADD}}$, for the risk averse: $\mathrm{n}^{* \mathrm{AON}}<\mathrm{n}^{* \mathrm{MULT}}<\mathrm{n}^{* \mathrm{ADD}}$. For the risk loving, the opposite is true: $\mathrm{n}^{* \mathrm{ADD}}<\mathrm{n}^{* \mathrm{MULT}}<n^{* A O N}$. For the risk neutral, the optimal effort is the same under all specifications for the noise in the production function so that $\mathrm{n}^{* \mathrm{AON}}=\mathrm{n}^{* \mathrm{MULT}}=\mathrm{n}^{* \mathrm{ADD}}$, and is determined from $p-c^{\prime}(n)=0$.

Proof. $n^{* A O N}=n^{* M U L T}=n^{* A D D}$ for the risk neutral follows from their utility being linear and hence their marginal utility being constant. Their marginal utility being constant reduces the covariance terms in the basic secondorder condition (2) to zero. Also, the linearity of the utility function implies ${ }^{17} \operatorname{cov}_{\epsilon}\left[u(I+n \epsilon-c(n)), \frac{f^{\prime}(\epsilon, n)}{f(\epsilon, n)}\right]=0$, leaving $E_{\epsilon}\left[\left(g^{\prime}(n, \epsilon)-c^{\prime}(n)\right)\right]=p-c^{\prime}(n)=0$ as the only condition that the optimal effort must satisfy in all three cases: ADD, MULT, and AON.

Turning to the risk averse, we first prove that $n^{* M U L T}<n^{* A D D}$ by evaluating the first-order condition (4a) for the optimal effort under MULT at $n^{* A D D}$.

(A1.1)

$$
\begin{aligned}
& E U_{M U L T}^{\prime}\left(n^{* A D D}\right) \\
& =\underbrace{E_{\epsilon}\left[u^{\prime}\left(I+n^{* A D D} \epsilon-c\left(n^{* A D D}\right)\right)\right] \cdot E_{\epsilon}\left[\left(\epsilon-c^{\prime}\left(n^{* A D D}\right)\right)\right]}_{=0} \\
& +\frac{1}{2} \cdot \underbrace{\operatorname{cov}_{\epsilon}\left[u^{\prime}\left(I+n^{* A D D} \epsilon-c\left(n^{* A D D}\right)\right), \epsilon-c^{\prime}\left(n^{* A D D}\right)\right]}_{<0}<0 .
\end{aligned}
$$

The covariance term in (A1.1) is negative because, for the risk averse, the marginal utility decreases with $\epsilon$ whereas the marginal product of effort, $g^{\prime}(n, \epsilon)=\epsilon$, increases with $\epsilon$. Because the sign of the first-order condition (A1.1) is negative, $n^{* M U L T}$, which brings (A1.1) to zero, must be less than $n^{* A D D}$.

To prove that $n^{* A O N}<n^{* M U L T}$ for the risk averse, we introduce an expression

$$
\begin{aligned}
\widetilde{E U}_{M U L T}^{\prime}(n) & =\int_{0}^{1} u^{\prime}(I+g(n, \epsilon)-c(n))\left(\epsilon-c^{\prime}(n)\right) f(\epsilon, n) d \epsilon \\
& <E U_{M U L T}^{\prime}(n),
\end{aligned}
$$

evaluate it at $n^{* A O N}$ and compare it with $E U_{A O N}^{\prime}\left(n^{* A O N}\right)$ in (5). ${ }^{18}$ After some rearrangement of the terms, the difference

17. $\operatorname{cov}_{\epsilon}\left[u(I+n \epsilon-c(n)) \frac{f^{\prime}(\epsilon n)}{f(\epsilon n)}\right]=0$ for the $\mathrm{AON}$ and ADD cases because $f^{\prime}(\epsilon, n)=0$ in those cases. For the case of MULT, $\frac{f^{\prime}(\epsilon n)}{f(\epsilon n)}=\frac{1}{2 n}-\frac{(\epsilon-p)^{2}}{2 p(1-p)}$, which is an even function of $\epsilon-p$, whereas the linear utility is an odd function of $\epsilon-p$. Therefore, $\operatorname{cov}_{\epsilon}\left[u(I+n \epsilon-c(n)) \frac{f^{\prime}(\epsilon n)}{f(\epsilon n)}\right]=0$ for the risk neutral under MULT.

18. The integrand in $\widetilde{E U}_{M U L T}^{\prime}(n)$ is negative while that in $E U_{M U L T}^{\prime}(n)$ is positive on the interval $2 c^{\prime}(n)-p<\epsilon<c^{\prime}(n)$ (recall Equation 4b), which is nonempty because $c^{\prime}(n)<p$ for the risk averse. Outside this interval, both integrands have the same sign. Hence, $\widetilde{E U}_{M U L T}^{\prime}(n)<E U_{M U L T}^{\prime}(n)$. between $\widetilde{E U}_{M U L T}^{\prime}\left(n^{* A O N}\right)$ and $E U_{A O N}^{\prime}\left(n^{* A O N}\right)$ becomes

$$
\begin{aligned}
& \widetilde{E U}_{M U L T}^{\prime}\left(n^{* A O N}\right)-E U_{A O N}^{\prime}\left(n^{* A O N}\right) \\
& =\left(1-c^{\prime}\left(n^{* A O N}\right)\right) Z+c^{\prime}\left(n^{* A O N}\right) W,
\end{aligned}
$$

where $Z=\int_{0}^{1} u^{\prime}\left(I+n^{* A O N} \epsilon-c\left(n^{* A O N}\right)\right) \epsilon f\left(\epsilon, n^{* A O N}\right) d \epsilon-p u \prime$ $\left(I+n^{* A O N}-c\left(n^{* A O N}\right)\right)$ and $W=(1-p) u^{\prime}\left(I-c\left(n^{* A O N}\right)\right)-$ $\int_{0}^{1} u^{\prime}\left(I+n^{* A O N} \epsilon-c\left(n^{* A O N}\right)\right)(1-\epsilon) f\left(\epsilon, n^{* A O N}\right) d \epsilon$. By concavity of the utility function for the risk averse,

$$
\begin{aligned}
& u^{\prime}(I+n-c(n))<\int_{0}^{1} u^{\prime}(I+n \epsilon-c(n)) \\
& \times f(\epsilon, n) d \epsilon<u \prime(I-c(n))
\end{aligned}
$$

for any $n$. The inequalities in (A1.3) imply $Z>0$, since $E_{\epsilon}(\epsilon)=p$, and $W>0$, since $E_{\epsilon}(1-\epsilon)=1-p$. Therefore, $E U_{M U L T}^{\prime}\left(n^{* A O N}\right)>\widetilde{E U}_{M U L T}^{\prime}\left(n^{* A O N}\right)>E U_{A O N}^{\prime}\left(n^{* A O N}\right)=0$ for the risk averse, implying $n^{* A O N}<n^{* M U L T}$.

For the risk loving, whose utility function is convex, $\widetilde{E U}_{M U L T}^{\prime}(n)>E U_{M U L T}^{\prime}(n)$ and the inequalities in (A1.3) reverse, implying $n^{* A O N}>n^{* M U L T}$. The statement $n^{* M U L T}>n^{* A D D}$ for the risk loving follows from (A1.1) because their marginal utility increases with $\epsilon$.

PROPOSITION 3. The optimal effort levels under multiplicative noise, $\mathrm{n}^{* \mathrm{MULT}}$, and all or nothing, $\mathrm{n}^{* \mathrm{AON}}$, both decrease with risk aversion.

Proof. Pratt's (1964) Theorem 1 states that if an agent with a utility function $u_{1}(x)$ has greater risk aversion than another agent with a utility function $u_{2}(x)$ for all $x$,

$$
\frac{u_{1}(d)-u_{1}(c)}{u_{1}(b)-u_{1}(a)}<\frac{u_{2}(d)-u_{2}(c)}{u_{2}(b)-u_{2}(a)}
$$

for all $a<b \leq c<d$. In particular, $\frac{u_{1}^{\prime}(x)}{u_{1}^{\prime}(y)}<\frac{u_{2}^{\prime}(x)}{u_{2}^{\prime}(y)}$ for all $y<x$. The above result applied to the first-order condition under AON,

$$
\begin{aligned}
0= & E U_{A O N}^{\prime}\left(n^{* A O N}\right)=u^{\prime}\left(I-c\left(n^{* A O N}\right)\right) \\
& {\left[p\left(1-c^{\prime}\left(n^{* A O N}\right)\right) \frac{u^{\prime}\left(I+n^{* A O N}-c\left(n^{* A O N}\right)\right)}{u^{\prime}\left(I-c\left(n^{* A O N}\right)\right)}\right.} \\
& \left.-(1-p) c^{\prime}\left(n^{* A O N}\right)\right],
\end{aligned}
$$

implies the optimal effort $n^{* A O N}$ will go down as increasing risk aversion reduces the ratio $\frac{u^{\prime}\left(I+n^{* A O N}-c\left(n^{* A O N}\right)\right)}{u^{\prime}\left(I-c\left(n^{* A O N}\right)\right)}$.

Turning to multiplicative noise, rewrite the first-order condition (4b) as

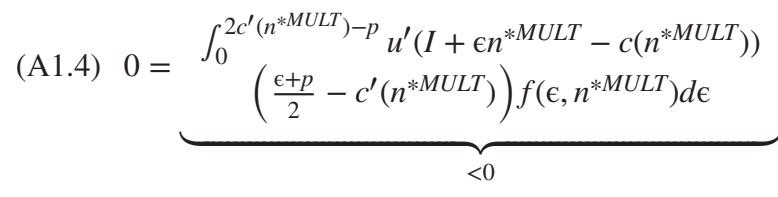

$$
\begin{aligned}
& +\underbrace{\begin{array}{l}
\int_{2 c^{\prime}\left(n^{* M U L T}\right)-p} u^{\prime}\left(I+\epsilon n^{* M U L T}-c\left(n^{* M U L T}\right)\right) \\
\left(\frac{\epsilon+p}{2}-c^{\prime}\left(n^{* M U L T}\right)\right) f\left(\epsilon, n^{* M U L T}\right) d \epsilon
\end{array}}_{>0}
\end{aligned}
$$

Pratt's (1964) theorem means that as risk aversion increases, the marginal utility in the positive part of (A1.4) 
will decrease relative to the marginal utility in the negative part. Therefore, the optimal effort $n^{* M U L T}$ will decrease with risk aversion to restore the equality in (A1.4).

PROPOSITION 4. The difference between optimal effort levels under MULT and AON increases with risk aversion.

Proof. The proof follows from Equation (A1.2) that specifies the difference between the first-order conditions for the optimal effort under MULT and AON evaluated at $n^{* A O N}$ :

$$
\begin{gathered}
\widetilde{E U}_{M U L T}^{\prime}\left(n^{* A O N}\right)-E U_{A O N}^{\prime}\left(n^{* A O N}\right)=\left(1-c^{\prime}\left(n^{* A O N}\right)\right. \\
\left(\int_{0}^{1} u^{\prime}\left(I+n^{* A O N} \epsilon-c\left(n^{* A O N}\right)\right) \epsilon f\left(\epsilon, n^{* A O N}\right) d \epsilon\right. \\
\left.-p u^{\prime}\left(I+n^{* A O N}-c\left(n^{* A O N}\right)\right)\right) \\
+c^{\prime}\left(n^{* A O N}\right)\left((1-p) u^{\prime}\left(I-c\left(n^{* A O N}\right)\right)\right. \\
\left.-\int_{0}^{1} u^{\prime}\left(I+n^{* A O N} \epsilon-c\left(n^{* A O N}\right)\right)(1-\epsilon) f\left(\epsilon, n^{* A O N}\right) d \epsilon\right)
\end{gathered}
$$

By Pratt's (1964) theorem, the ratios $\frac{u^{\prime}\left(I+n^{* A O N} \in-c\left(n^{* A O N}\right)\right)}{u^{\prime}\left(I+n^{* A O N}-c\left(n^{* A O N}\right)\right)}$ and $\frac{u^{\prime}\left(I-c\left(n^{* A O N}\right)\right)}{u^{\prime}\left(I+n^{* A O N}-c\left(n^{* A O N}\right)\right)}$ will increase with risk aversion for all $\epsilon \in[0,1]$. Hence, $\widetilde{E U}_{M U L T}^{\prime}\left(n^{* A O N}\right)-E U_{A O N}^{\prime}\left(n^{* A O N}\right)$ will increase with risk aversion, and so will the difference between $n^{* M U L T}$ and $n^{* A O N}$.

PROPOSITION 5. The variance of individual effort choices increases from ADD to MULT to AON: $\operatorname{var}\left(\mathrm{n}^{* \mathrm{AON}}\right)>\operatorname{var}\left(\mathrm{n}^{* \mathrm{MULT}}\right)>\operatorname{var}\left(\mathrm{n}^{* \mathrm{ADD}}\right)=0$.

Proof. $\operatorname{var}\left(n^{* A D D}\right)=0$ by Proposition 1 that states that every agent's effort choice is determined by $p-c^{\prime}\left(n^{* A D D}\right)=0$ and is independent of risk preferences. $\operatorname{var}\left(n^{* M U L T}\right)>\operatorname{var}\left(n^{* A D D}\right)$ because under MULT, unlike ADD, effort varies with risk aversion. $\operatorname{var}\left(n^{* A O N}\right)>\operatorname{var}\left(n^{* M U L T}\right)$ because Proposition 4 implies a greater variation of effort level with risk aversion under AON and hence a greater dispersion of individual effort choices.

\section{APPENDIX B: THE CASE OF LOSS AVERSION}

Throughout the paper we have considered the case of an agent whose risk preferences may be non-neutral. Here, to separate risk aversion from loss aversion, we present key analytical results for the case of an agent who is risk neutral but loss averse. All notation is the same as above, unless specified otherwise. The derivations that are the same as in Appendix 1 are skipped for brevity.

The agent's assumed utility function is

$$
\begin{aligned}
& u(I+g(n, \epsilon)-c(n))=w_{0}(n) \\
& +\left\{\begin{array}{l}
\lambda \cdot\left(I+g(n, \epsilon)-c(n)-w_{0}\right) \text { if } I+g(n, \epsilon)-c(n) \leq w_{0}(n) \\
I+g(n, \epsilon)-c(n)-w_{0}(n) \text { otherwise }
\end{array}\right.
\end{aligned}
$$

where $w_{0}(n)$ is the reference income and $\lambda \geq 1$ is the loss aversion parameter. We consider two specifications for the reference income: a constant $w_{0}(n)=w_{0}$ (for example, the initial endowment in our experiment), and the reference income equal to the expected income, that is $w_{0}(n)=g(n, E(\epsilon))-c(n)$.
The agent maximizes expected utility

$$
\begin{gathered}
\max _{n} E U(n)=w_{0}(n)+\int_{-\infty}^{\infty}\left(I+g(n, \epsilon)-c(n)-w_{0}(n)\right) f(\epsilon, n) d \epsilon \\
+(\lambda-1) \cdot \int_{-\infty}^{\epsilon_{0}(n)}\left(I+g(n, \epsilon)-c(n)-w_{0}(n)\right) f(\epsilon, n) d \epsilon
\end{gathered}
$$

where $\epsilon_{0}(n)$ solves $I+g\left(n, \epsilon_{0}(n)\right)-c(n)=w_{0}(n)$. The optimal level of effort is determined from the following first-order condition:

$$
\begin{aligned}
& 0= E U^{\prime}(n)=w_{0}^{\prime}(n)+\int\left(g^{\prime}(n, \epsilon)-c^{\prime}(n)-w_{0}^{\prime}(n)\right) f(\epsilon, n) d \epsilon \\
&+\int\left(I+g(n, \epsilon)-c(n)-w_{0}(n)\right) \cdot \frac{f^{\prime}(\epsilon, n)}{f(\epsilon, n)} f(\epsilon, n) d \epsilon \\
&+(\lambda-1) \cdot \int_{-\infty}^{\epsilon_{0}(n)}\left(g^{\prime}(n, \epsilon)-c^{\prime}(n)-w_{0}^{\prime}(n)\right) f(\epsilon, n) d \epsilon \\
&+(\lambda-1) \cdot \int_{-\infty}^{\epsilon_{0}(n)}\left(I+g(n, \epsilon)-c(n)-w_{0}(n)\right) \cdot \frac{f^{\prime}(\epsilon, n)}{f(\epsilon, n)} f(\epsilon, n) d \epsilon
\end{aligned}
$$

As in the case of a risk-averse agent, presented in the main text, the first-order conditions for each of our experimental treatments can be derived from the above, resulting in the following expressions.

ADD:

$$
\begin{gathered}
0=p-c^{\prime}\left(n^{* A D D}\right)+(\lambda-1) \\
\int_{-\infty}^{\epsilon_{0}\left(n^{* A D D}\right)}\left(p-c^{\prime}\left(n^{* A D D}\right)-w_{0}^{\prime}\left(n^{* A D D}\right)\right) f(\epsilon, n) d \epsilon
\end{gathered}
$$

MULT (use Equation 4b):

$$
\cdot \int_{-\infty}^{\epsilon_{0}\left(n^{* M U L T}\right)}\left(\frac{\epsilon+p}{2}-c^{\prime}\left(n^{* M U L T}\right)-w_{0}^{\prime}\left(n^{* M U L T}\right)\right) f(\epsilon, n) d \epsilon .
$$

AON (assuming the reference income is earned only in the event of success, with probability $p$ ):

$$
\begin{gathered}
\cdot\left(-c^{\prime}\left(n^{* A O N}\right)-w_{0}^{\prime}\left(n^{* A O N}\right)\right) \\
=p-c^{\prime}\left(n^{* A O N}\right)+(\lambda-1) \\
\cdot \int_{-\infty}^{\epsilon_{0}\left(n^{* A O N}\right)}\left(0-c^{\prime}\left(n^{* M U L T}\right)-w_{0}^{\prime}\left(n^{* M U L T}\right)\right) f(\epsilon, n) d \epsilon .
\end{gathered}
$$$$
0=p-c^{\prime}\left(n^{* A O N}\right)+(\lambda-1) \cdot(1-p)
$$

The propositions analogous to Propositions 1-5 for the risk-aversion case (Appendix 1) follow directly from the above first-order conditions:

PROPOSITION 1a. The optimal effort choice under additive noise, $n^{* A D D}$, is unaffected by loss aversion and is determined by the condition $p-c^{\prime}\left(n^{* A D D}\right)=0$.

Proof. When the reference income is constant, $w_{0}(n)=w_{0}$, $w_{0}^{\prime}(n)=0$, the first-order condition (A2.1) becomes $0=\left(p-c^{\prime}\left(n^{* A D D}\right)\right) \cdot\left(1+(\lambda-1) \cdot F\left(n^{* A D D}\right)\right)$. With $\quad(1+(\lambda$ $\left.-1) \cdot F\left(n^{* A D D}\right)\right)>0$ for all finite $n^{* A D D}, n^{* A D D}$ is determined by $p-c^{\prime}\left(n^{* A D D}\right)=0$ and is independent of loss aversion. For the case of expectation-based reference income, $w_{0}(n)=g(n, E(\epsilon))-c(n), w_{0}^{\prime}(n)=p-c^{\prime}(n)$, the first-order condition (A2.1) becomes $0=p-c^{\prime}\left(n^{* A D D}\right)$, implying, again, that $n^{* A D D}$ is independent of loss aversion.

PROPOSITION 2a. The optimal effort under all or nothing, $n^{* A O N}$, is lower than that under multiplicative noise, $n^{* M U L T}$, 
which in turn is lower than that under additive noise, $n^{*} A D D$, for the loss-averse $(\lambda>1): n^{* A O N}<n^{* M U L T}<n^{* A D D}$. For the loss-neutral $(\lambda=1)$, the optimal effort is the same under all specifications for the noise in the production function so that $n^{* A O N}=n^{* M U L T}=n^{* A D D}$, and is determined from $p-c^{\prime}(n)=0$.

PROPOSITION 3a. The optimal effort levels under multiplicative noise, $n^{* M U L T}$, and all or nothing, $n^{* A O N}$, both decrease with loss aversion.

PROPOSITION 4a. The difference between optimal effort levels under MULT and AON increases with loss aversion.

PROPOSITION 5a. The variance of individual effort choices increases from ADD to MULT to AON: $\operatorname{var}\left(n^{* A O N}\right)>\operatorname{var}\left(n^{* M U L T}\right)>\operatorname{var}\left(n^{* A D D}\right)=0$.

Proof. With $\lambda=1$ the first-order conditions (A2.1)-(A2.3) are the same and the optimal effort is determined from $p-c^{\prime}(n)=0$. For $\lambda>1$, note that $0 \geq \int_{-\infty}^{\epsilon_{0}(n)}\left(p-c^{\prime}(n)-\right.$ $\left.w_{0}^{\prime}(n)\right) f(\epsilon, n) d \epsilon>\int_{-\infty}^{\epsilon_{0}(n)}\left(\frac{\epsilon+p}{2}-c^{\prime}(n)-w_{0}^{\prime}(n)\right) f(\epsilon, n) d \epsilon>$ $\int_{-\infty}^{\epsilon_{0}(n)}\left(0-c^{\prime}(n)-w_{0}^{\prime}(n)\right) f(\epsilon, n) d \epsilon$ for a given finite $n$ and for both specifications of the reference income $w_{0}(n)$. This fact implies that the optimal effort choices in the MULT and AON are progressively below the benchmark $p-c^{\prime}(n)=0$ in ADD for a given $\lambda>1$, thus proving Proposition 2a. The fact that $\lambda$ enters the first-order conditions (A2.2)-(A2.3) as a multiplier on their negative parts proves Propositions $3 \mathrm{a}$ and 4a. Progressively higher sensitivity of effort choices to loss aversion proves Proposition 5a.

\section{REFERENCES}

Ariely, D., U. Gneezy, G. Loewenstein, and N. Mazar. "Large stakes and big mistakes." Review of Economic Studies, 76(2), 2009, 451-69.

Baker, G. P., and B. Jorgensen. "Volatility, Noise, and Incentives." 2003. Accessed June 2019. http://www.people .hbs.edu/gbaker/oes/papers/Baker_Jorgensen.pdf.

Baumeister, R. F. "Choking under Pressure: SelfConsciousness and Paradoxical Effects of Incentives on Skillful Performance." Journal of Personality and Social Psychology, 46(3), 1984, 610-20.

Baumeister, R. F., and C. J. Showers. "A Review of Paradoxical Performance Effects: Choking under Pressure in Sports and Mental Tests." European Journal of Social Psychology, 16(4), 1986, 361-83.

Beaud, M., and M. Willinger. "Are people risk vulnerable?" Management Science, 61(3), 2015, 624-36.

Bellemare, C., and B. Shearer. "Sorting, Incentives and Risk Preferences: Evidence from a Field Experiment." Economics Letters, 108(3), 2010, 345-8.

Berg, J., J. Dickhaut, and K. McCabe. "Trust, Reciprocity, and Social History." Games and Economic Behavior, 10(1), 1995, 122-42.

Binswanger, H. P. "Attitudes toward Risk: Experimental Measurement in Rural India." American Journal of Agricultural Economics, 62(3), 1980, 395-407.

Brooks, P., and H. Zank. "Loss Averse Behavior." Journal of Risk and Uncertainty, 31(3), 2005, 301-25.

Bull, C., A. Schotter, and K. Weigelt. "Tournaments and Piece Rates: An Experimental Study." Journal of Political Economy, 95(1), 1987, 1-33.

Cadsby, C. B., F. Song, and F. Tapon. "Sorting and Incentive Effects of Pay for Performance: An Experimental Investigation." Academy of Management Journal, 50(2), 2007, 387-405.
Cadsby, C. B., Song, F. and Tapon, F. 2016. The Impact of Risk Aversion and Stress on the Incentive Effect of Performance Pay. Research in Experimental Economics Vol.19, Experiments in Organizational Economics, S. Goerg and J. Hammon, series editors R.M. Isaac and D.A. Norton, Emerald Group Publishing, pp. $189-227$.

de Figueiredo, R., E. Rawley, and O. Shelef. "Bad Bets: Excessive Risk Taking, Convex Incentives, and Performance." Stanford Institute for Economic Policy Research Discussion Paper 13-002, 2013.

Dohmen, T., A. Falk, D. Huffman, U. Sunde, J. Schupp, and G. Wagner. "Individual Risk Attitudes: Measurement, Determinants and Behavioral Consequences." Journal of the European Economic Association, 9(3), 2011, 522-50.

Eckel, C., and P. Grossman. "Sex Differences and Statistical Stereotyping in Attitudes towards Financial Risk." Evolution and Human Behavior, 23(4), 2002, 281-95.

- "Forecasting Risk Attitudes: An Experimental Study Using Actual and Forecast Gamble Choices." Journal of Economic Behavior and Organization, 68(1), 2008, $1-7$.

Fehr, E., G. Kirchsteiger, and A. Riedl. "Does Fairness Prevent Market Clearing? An Experimental Investigation." The Quarterly Journal of Economics, 108(2), 1993, 437-59.

Fischbacher, U. "Z-Tree: Zurich Toolbox for Ready-Made Economic Experiments." Experimental Economics, 10(2), 2007, 171-8.

Franke, G., H. Schlesinger, and R. C. Stapleton. "Multiplicative Background Risk." Management Science, 52(1), 2006, 146-53.

Gibson, J. and D. Johnson. "The Economic Relevancy of Risk Preferences Elicited Online and with Low Stakes." Unpublished working paper, 2018.

Gollier, C., and J. W. Pratt. "Risk Vulnerability and the Tempering Effect of Background Risk." Econometrica, 64(5), 1996, 1109-23.

Grund, C., and D. Sliwka. "Evidence of Performance Pay and Risk Aversion." Economics Letters, 102, 2010, 8-11.

Holt, C., and S. Laury. "Risk Aversion and Incentive Effects." American Economic Review, 92(5), 2002, 1644-55.

Koudstaal, M., R. Sloof, and M. vanPraag. "Risk, Uncertainty, and Entrepreneurship: Evidence from a Lab-inthe-Field Experiment." Management Science, 62(10), 2016, 2897-915.

Lo, H.-F., M. Ghosh, and F. Lafontaine. "The Incentive and Selection Roles of Sales Force Compensation Contracts." Journal of Marketing Research, 48(4), 2011, 781-98.

Lönnqvist, J.-E., M. Verkasalo, G. Walkowitz, and P. C. Wichard. "Measuring Individual Risk Attitudes in the Lab: Task or Ask? An Empirical Comparison." Journal of Economic Behavior and Organization, 119, 2015, 254-66.

Pratt, J. "Risk Aversion in the Small and in the Large." Econometrica, 32(1/2), 1964, 122-36.

Raith, M. "Specific Knowledge and Performance Measurement." RAND Journal of Economics, 39(4), 2008, 1059-79.

Rantakari, H. "On the Role of Uncertainty in the RiskIncentives Trade-off." The B.E. Journal of Theoretical Economics, 8, 2008, 1-23.

Reynaud, A., and S. Couture. "Stability of Risk Preference Measures: Results from a Field Experiment on French Farmers." Theory and Decision, 73(2), 2012, 203-21.

Sharpe, W. F. "Capital Asset Prices: A Theory of Market Equilibrium under Conditions of Risk." Journal of Finance, 19(3), 1964, 425-42. 
Sloof, R., and C. M. vanPraag. "Performance Measurement, Expectancy and Agency Theory: An Experimental Study." Journal of Economic Behavior and Organization, 67(3-4), 2008, 794-809.

"The Effect of Noise in a Performance Measure on Work Motivation: A Real Effort Laboratory Experiment." Labour Economics, 17(5), 2010, 751-65.

Tobin, J. "Liquidity Preference as Behavior towards Risk." The Review of Economic Studies, 25(2), 1958, 65-86.

Zabojnik, J. "Pay-Performance Sensitivity and Production Uncertainty." Economics Letters, 53(3), 1996, 291-6.
Zubanov, N. "Risk Aversion and Effort in an Incentive Pay Scheme with Multiplicative Noise: Theory and Experimental Evidence." Evidence-based HRM: A Global Forum for Empirical Scholarship, 3(2), 2015, 130-44. 